\title{
A Six-Sigma approach for comparing diagnostic errors in healthcare - where does laboratory medicine stand?
}

\author{
Giuseppe Lippi ${ }^{1}$, Mario Plebani $^{2}$ \\ ${ }^{1}$ Section of Clinical Biochemistry, University of Verona, Verona, Italy; ${ }^{2}$ Department of Laboratory Medicine, University Hospital of Padova, Padova, \\ Italy \\ Correspondence to: Prof. Giuseppe Lippi. Section of Clinical Biochemistry, University Hospital of Verona, Piazzale LA Scuro, Verona, Italy. \\ Email: giuseppe.lippi@univr.it or ulippi@tin.it.
}

Submitted Mar 20, 2018. Accepted for publication Mar 30, 2018.

doi: $10.21037 / \mathrm{atm} .2018 .04 .02$

View this article at: http://dx.doi.org/10.21037/atm.2018.04.02

Laboratory medicine has been one of the most proactive disciplines in establishing a culture of quality and safety, throughout a long endeavour that has commenced more than 100 years ago, in the $19^{\text {th }}$ century (1). As a paradigmatic example, many working groups or task forces on quality in diagnostic testing have been endorsed by several national and international organizations, such as the International Federation of Clinical Chemistry [i.e., the IFCC Working Group Laboratory Errors and Patient Safety (WGLEPS)], or the European Federation of Clinical Chemistry and Laboratory Medicine [i.e., the EFLM Working Groups Harmonisation of Total Testing Process (WGH), Preanalytical Phase (WE-PRE) and Postanalytical Phase (WG-POST)]. Certification and accreditation of laboratory services are other important attributes which have both enormously contributed to moderate diagnostic uncertainty (2). Although the enormous efforts made for improving standardization and/or harmonization in the various activities of the total testing process have now contributed to render laboratory diagnostics a much safer enterprise, with an over 300-fold decrease in the error rate since the birth of the discipline (3), medical laboratories are not the safe places they are supposed to be, and many opportunities of errors remain, most of which occurring in the extra-analytical phases of the total testing process (4).

Benchmark, which can be conventionally defined as a process aimed to define a standard of excellence and to compare functions or activities with a reference measure (5), is indeed one of the most important strategies for risk assessment and prevention, as well as for harm containment in healthcare (6). Briefly, the widespread adoption of a set of reliable and universally agreed performance indicators may allow to accurately compare individual performance, identifying local areas of vulnerability, generating a wealthy spirit of competition with partners and finally leading to implementing best healthcare practices (7). Unquestionably, laboratory professionals and their societies have been forerunners even in benchmarking. Recent examples include the IFCC WG-LEPS project on Quality Indicators in laboratory medicine (8) or the joint IFCC WG-LEPS and EFLM WG-PRE initiative to developing a standardized software for recording laboratory errors (9). This large collaborative effort has allowed the many participant laboratories to enter their local data in a standardized database, and thus benchmarking their actual performance with that of several other facilities worldwide. Nevertheless, what has not been definitely clarified so far is how the error rate in laboratory medicine compares with that of other common diagnostic disciplines such as radiology, pathology and ecography.

According to the most recent and accurate information retrieved from the current scientific literature, the error rate in laboratory diagnostics is approximately $0.3 \%(10)$, thus much lower than the risk of mistakes in ecography (i.e., $0.8 \%$ ) (11), radiology (i.e., 4\%) (12) and pathology (i.e., $0.5 \%$ ) (13). The error rate in laboratory medicine is even lower than the risk of losing baggage in an Airport (14), which is a well-established quality indicator of customer satisfaction in commercial aviation (15) (Table 1). A much better description of these figures can be obtained using the Six-Sigma approach, a clear-cut approach for allowing system (re-)design and for process management 
Table 1 Statistics of diagnostic errors in laboratory medicine, pathology, radiology and ecography compared to the number of baggage lost in airports

\begin{tabular}{lcc}
\hline Specialities & Frequency, \% & Six-Sigma SD \\
\hline Radiology & 4 & 3.25 \\
Pathology & 5 & 3.14 \\
Ecography & 0.80 & 3.91 \\
Laboratory medicine & 0.30 & 4.24 \\
Luggage lost in airport & 0.60 & 4.03 \\
\hline
\end{tabular}

$\mathrm{SD}$, standard deviation.

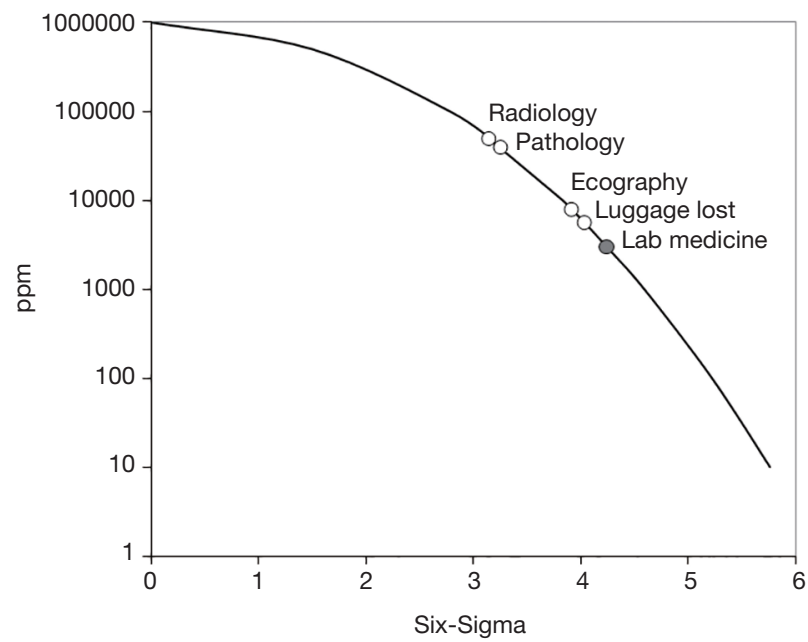

Figure 1 Six-Sigma chart of diagnostic errors in laboratory medicine, pathology, radiology and ecography compared to the number of baggage lost in airports. ppm, part per million.

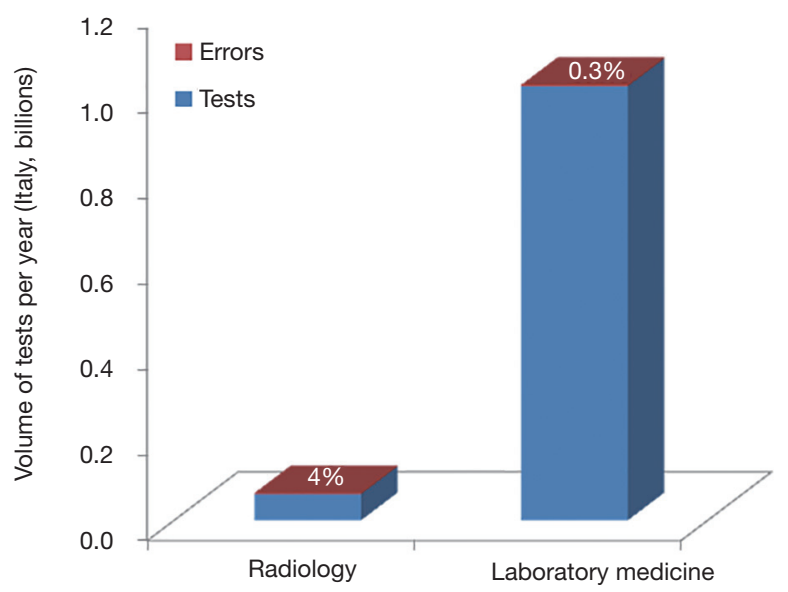

Figure 2 Volumes of tests and potential diagnostic errors in radiology and laboratory medicine in Italy (year 2013). and improvement (16). Based on its formula, six standard deviations (SDs) separating a measured variable (i.e., the error rate) and the closest specification limit implies that no single activity will actually fail to meet the expected specifications. To put it simply, the highest is the SD value in the Six-Sigma chart, the lowest is the chance of failure and vice versa (e.g., $6 \mathrm{SD}=3.4$ failures ppm, whilst $1 \mathrm{SD}=690,000$ failures ppm, respectively). Therefore, as clearly shown in Figure 1, the probability of errors in laboratory medicine is approximately half of the likelihood that a baggage will be lost in an airport and, even more impressively, is nearly 13 - and 17 -fold lower than the risk of mistakes in pathology and radiology, respectively.

These straightforward figures conflict with a widespread perception that the risk of errors in laboratory medicine is magnified compared to radiology. However, this conclusion is clearly biased by the different volume of tests performed by the two diagnostic disciplines. According to official statistics of the Italian Ministry of Health (17), a total number of 1.016 billion laboratory analyses and 0.061 billion radiology tests have been performed in the country throughout the year 2013, respectively. This translates into a potential risk of 2.43 million radiological mistakes and 3.05 million laboratory errors, respectively. Yet, despite clinical laboratories perform a volume of tests nearly 20 -fold higher than radiology departments, the overall number of potential errors is similar in absolute number, but is still consistently lower in percentage (Figure 2).

The results of this analysis lead the way to an important conclusion. Laboratory diagnostics is an essential science, which provides a fundamental, virtually inalienable, contribution to the clinical decision making, despite only modestly eroding the available healthcare resources (18). Unlike other diagnostic areas in medicine (19), error reduction strategies have now become routine part of comprehensive quality management programmes in clinical laboratories, and have probably allowed to make laboratory medicine the safest diagnostic discipline in healthcare.

\section{Acknowledgements}

None.

\section{Footnote}

Conflicts of Interest: The authors have no conflicts of interest to declare. 


\section{References}

1. Lippi G, Guidi GC, Plebani M. One hundred years of laboratory testing and patient safety. Clin Chem Lab Med 2007;45:797-8.

2. Plebani M, Lippi G. Uncertainty, quality, safety and accreditation in laboratory medicine. J Lab Precis Med 2017;2:80.

3. Plebani M. Diagnostic Errors and Laboratory MedicineCauses and Strategies. EJIFCC 2015;26:7-14.

4. Lippi G, Simundic AM. The EFLM strategy for harmonization of the preanalytical phase. Clin Chem Lab Med 2017. [Epub ahead of print].

5. Benson HR. An introduction to benchmarking in healthcare. Radiol Manage 1994;16:35-9.

6. Ettorchi-Tardy A, Levif M, Michel P. Benchmarking: a method for continuous quality improvement in health. Healthc Policy 2012;7:e101-19.

7. Lovaglio PG. Benchmarking strategies for measuring the quality of healthcare: problems and prospects. ScientificWorldJournal 2012;2012:606154.

8. Sciacovelli L, Lippi G, Sumarac Z, et al. Quality Indicators in Laboratory Medicine: the status of the progress of IFCC Working Group "Laboratory Errors and Patient Safety" project. Clin Chem Lab Med 2017;55:348-57.

9. Lippi G, Sciacovelli L, Simundic AM, et al. Innovative software for recording preanalytical errors in accord with the IFCC quality indicators. Clin Chem Lab Med 2017;55:e51-3.

Cite this article as: Lippi G, Plebani M. A Six-Sigma approach for comparing diagnostic errors in healthcare-where does laboratory medicine stand? Ann Transl Med 2018;6(10):180. doi: 10.21037/atm.2018.04.02
10. Carraro P, Plebani M. Errors in a stat laboratory: types and frequencies 10 years later. Clin Chem 2007;53:1338-42.

11. Brook OR, Kane RA, Tyagi G, et al. Lessons learned from quality assurance: errors in the diagnosis of acute cholecystitis on ultrasound and CT. AJR Am J Roentgenol 2011;196:597-604.

12. Brady AP. Error and discrepancy in radiology: inevitable or avoidable? Insights Imaging 2017;8:171-82.

13. Zarbo RJ, Meier FA, Raab SS. Error detection in anatomic pathology. Arch Pathol Lab Med 2005;129:1237-45.

14. The Telegraph. What on Earth happens to lost luggage? Available online: https://www.telegraph.co.uk/travel/ travel-truths/What-happens-to-lost-luggage/

15. US Department of Transportation. Air Travel Consumer Report. Available online: https://www.transportation.gov/ airconsumer/air-travel-consumer-reports

16. Ahmed S, Manaf NH, Islam R. Effects of Lean Six Sigma application in healthcare services: a literature review. Rev Environ Health 2013;28:189-94.

17. Italian Ministry of Health. Statistical Yearbook of the National Healthcare System - Year 2013. Available online: http://www.salute.gov.it/imgs/C_17_pubblicazioni_2536_ allegato.pdf

18. Lippi G, Plebani M. The add value of laboratory diagnostics: the many reasons why decision-makers should actually care. J Lab Precis Med 2017;2:100.

19. Graber ML. The incidence of diagnostic error in medicine. BMJ Qual Saf 2013;22 Suppl 2:ii21-7. 